\title{
Ochnaceae endémicas del Perú
}

Blanca León ${ }^{1,2}$

${ }^{1}$ Museo de Historia Natural, Av. Arenales 1256, Aptdo. 14-0434, Lima 14, Perú

2 Plant Resources Center, University of Texas at Austin, Austin TX 78712 EE.UU.

blanca.leon@mail.utexas.edu

\section{Resumen}

Esta es una de las familias que constituye una novedad para la flora endémica peruana. La familia Ochnaceae es reconocida en el Perú por presentar siete géneros y 25 especies (Brako \& Zarucchi, 1993; Ulloa Ulloa et al., 2004), la mayoría arbustos y árboles. En este trabajo reconocemos tres especies endémicas en dos géneros. Las especies endémicas se encuentran en las regiones Bosques Muy Húmedos Premontanos y Bosques Húmedos Amazónicos, entre los 260 y 1380 m de altitud. Dos de las especies endémicas se encuentran dentro del Sistema Nacional de Áreas Naturales Protegidas por el Estado.

Palabras claves: Ochnaceae, Perú, endemismo, plantas endémicas.

\section{Abstract}

This family is one of the novelties for the Peruvian endemic flora. The Ochnaceae are represented in Peru by seven genera and 25 species (Brako \& Zarucchi, 1993; Ulloa Ulloa et al., 2004), mostly shrubs and trees. Here we recognize three endemic species in two genera. These species grow in Humid Lowland Amazonian Forests and Very Humid Premontane Forests regions, between 260 and $1380 \mathrm{~m}$ elevation. Two species have been recorded in the Peruvian System of Protected Natural Areas.

Keywords: Ochnaceae, Peru, endemism, endemic plants.

\section{Ouratea megaphylla Sastre}

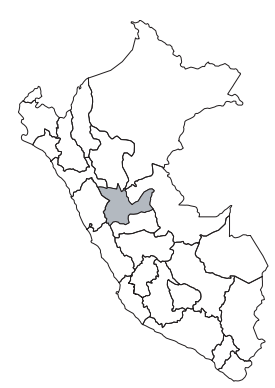

\section{CR, B1ab(iii)}

Publicación: Ann. Naturhist. Mus. Wien, Ser. B, Bot. Zool. 98B: 573—574, f. 1. 1996. Colección tipo: W. Morawetz \& B. Wallnöfer 17-27985

Herbarios: LZ, P, W; USM!.

Nombre común: Desconocido.

Registro departamental: HU.

Regiones Ecológicas: BHA; $260 \mathrm{~m}$.

SINANPE: Sin registro.

Herbarios peruanos: USM (isotipo).

Observaciones: Árbol conocido solamente de la colección tipo, una planta recolectada en 1985, de la cuenca del Pachitea. Esta especie podría estar representada en la Reserva Comunal del Sira. Amenazas a sus poblaciones podrían estar asociadas a deforestación, se requiere también conocer sobre la historia natural de esta especie.

\section{Ouratea wallnoeferiana Sastre}

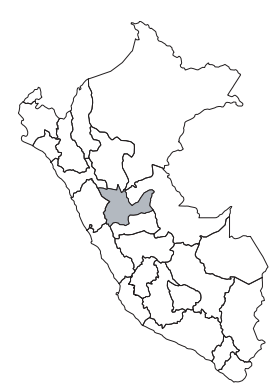

\section{CR, B1ab(iii)}

Publicación: Ann. Naturhist. Mus. Wien, Ser. B, Bot. Zool. 98B: 575, f. 3. 1996.

Colección tipo: B. Wallnöfer 12-31088

Herbarios: LZ, P, W; USM.

Nombre común: Desconocido.

Registro departamental: HU.

Regiones Ecológicas: BMHP; $800 \mathrm{~m}$.

SINANPE: RCS

Herbarios peruanos: USM (isotipo citado+1).

Observaciones: Árbol conocido solamente del centro oriente del país; donde ha sido recolectada en la cuenca del Pachitea, en el área de la Reserva Comunal del Sira, la cual alberga varios endemismos. Fue hallada en bosques premontanos.

\section{Perissocarpa ondox B. Walln.}

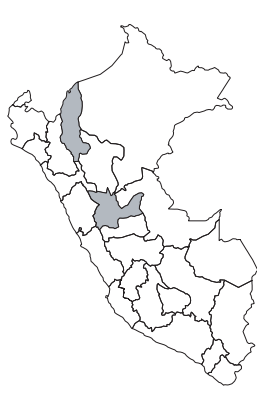

EN, B1ab(iii)

Publicación: Ann. Naturhist. Mus. Wien, Ser. B, Bot. Zool. 100: 694, 696, 698, f. 5, 6. 1998.

Colección tipo: W. Morawetz \& B. Wallnöfer 16-2288

Herbarios: F, G, K, MO, NY, LZ, W; USM!

Nombre común: Desconocido.

Registro departamental: AM, HU.

Regiones Ecológicas: BMHP; 900-1380 $\mathrm{m}$.

SINANPE: RCS

Herbarios peruanos: USM (isotipo+8).

Observaciones: Árbol conocido de poblaciones fragmentadas, la mayoría del centro del país, con una población disyunta en el norte. $\mathrm{Al}$ parecer es una especialista de hábitat, ocupando bosques en cimas de cordilleras, sobre suelos con capa húmica gruesa. La mayoría de los registros provienen de la cuenca del Pachitea. 